\title{
Noncoding RNAs in Duchenne and Becker muscular dystrophies: role in pathogenesis and future prognostic and therapeutic perspectives
}

\author{
Roberta Brusa $^{1} \cdot$ Francesca Magri $^{1} \cdot$ Nereo Bresolin $^{1,2} \cdot$ Giacomo Pietro Comi $^{2,3} \cdot$ Stefania Corti $^{1,2}$
}

\begin{abstract}
Noncoding RNAs (ncRNAs), such as miRNAs and long noncoding RNAs, are key regulators of gene expression at the post-transcriptional level and represent promising therapeutic targets and biomarkers for several human diseases, including Duchenne and Becker muscular dystrophies (DMD/BMD). A role for ncRNAs in the pathogenesis of muscular dystrophies has been suggested, even if it is still incompletely understood. Here, we discuss current progress leading towards the clinical utility of ncRNAs for DMD/BMD. Long and short noncoding RNAs are differentially expressed in DMD/BMD and have a mechanism of action via targeting mRNAs. A subset of muscle-enriched miRNAs, the so-called myomiRs (miR-1, miR-133, and miR-206), are increased in the serum of patients with DMD and in dystrophin-defective animal models. Interestingly, myomiRs might be used as biomarkers, given that their levels can be corrected after dystrophin restoration in dystrophic mice. Remarkably, further evidence demonstrates that ncRNAs also play a role in dystrophin expression; thus, their modulations might represent a potential therapeutic strategy with the aim of upregulating the dystrophin protein in combination with other oligonucleotides/gene therapy approaches.
\end{abstract}

Keywords Duchenne muscular dystrophy · Becker muscular dystrophy · lncRNA · miRNA · Biomarkers · Antisense oligonucleotides

\section{Introduction}

Duchenne muscular dystrophy (DMD) is one of the most common neuromuscular disorders in childhood, involving around 1 in 3500 male births [1] with an incidence from 10.71 to 27.78 per 100.000 males [2]. It is an X-linked disease, usually caused by out-of-frame mutations in the dystrophin gene $D M D$, which leads to the absence of protein expression. On the contrary, mutations retaining the reading frame are generally related to partial residual expression of dystrophin and a milder phenotype called Becker Muscular Dystrophy (BMD) [3].

Stefania Corti

stefania.corti@unimi.it

1 Neurology Unit, Foundation IRCCS Ca’ Granda Ospedale Maggiore Policlinico, Milan, Italy

2 Dino Ferrari Centre, Neuroscience Section, Department of Pathophysiology and Transplantation (DEPT), University of Milan, Milan, Italy

3 Neuromuscular and Rare Diseases Unit, Foundation IRCCS Ca’ Granda Ospedale Maggiore Policlinico, Milan, Italy
Dystrophin is a cytoplasmatic protein that plays a major structural role in skeletal muscles, linking the cytoskeleton to the extracellular matrix via a complex (dystrophin-associated protein complex or DAPC) formed with dystroglycans, sarcoglycans, sarcospan, dystrobrevins and syntrophin [4]. The disruption of this structure, especially the linking with actin and beta-dystroglycan, destabilizes the sarcolemma during the muscle contraction [5]. Membrane instability allows the entrance of calcium ions with subsequent oxidative stress, activation of $\mathrm{Ca}^{2+}$-dependent calpain and protein degradation. Activation of complement and infl causes necrosis and generation of pro-fibrotic factors. While muscle regeneration initially increases to replace muscle damage, over time, muscle regeneration fails and fibro-fatty substitution takes place, impairing the muscle function [6]. In fact, the prolonged exposure to an adverse environment prevents myogenesis, despite satellite cells retaining regenerative capacity [7].

Moreover, dystrophin has an important scaffolding role, participating in the cell signaling pathways [8] and enabling the correct localization of nitric oxide synthetase (nNOS) [9]. Other components of DAPC are also involved 
in signaling. For instance, beta-dystroglycan is involved in MAPK pathway, dystroglycans are cell surface receptors for protein of the extracellular matrix, syntrophin organizes several signaling proteins and interacts with ion channels and G-protein-related pathways [10]. The absence of this important scaffolding role can result in disrupted expression of several interrelating molecules.

DMD generally starts in early childhood with proximal muscle weakness leading to loss of ambulation at approximately 12 years of age. Diagnosis is usually achieved at 3 years of life due to motor delay, sural hypertrophy, falls or increased CK levels. When 6-year-old, the patients develop progressive difficulties in running, climbing stairs and rising from floor. The muscles most affected by fibrofatty degeneration are psoas, gluteus and quadriceps, followed by proximal muscles of upper limbs [11-13]. Cardiac involvement, starting from 10 years of age, leads to dilated cardiomyopathy and heart failure [14]. Death occurs within the third decade of life due to heart or respiratory failure [15]. On the other hand, BMD is a milder disease, although more heterogeneous, characterized by muscle weakness and atrophy with juvenile onset and sural hypertrophy. Loss of ambulation may occur at variable ages, even after 60 years of age [16]. Cardiomyopathy is less frequent than DMD but represents one of the most frequent causes of death in BMD subjects and it is not related to the level of skeletal muscle impairment [17].

To date, no definitive cure for dystrophinopathies is available, but novel therapeutic strategies have been attempted [18]. Recently, three novel therapies have been approved by the FDA (Eteplirsen and Golodirsen) and EMA (Ataluren). Exon skipping, mediated by oligonucleotides, allows for the production of a shorter but functional mRNA rescuing dystrophin expression and shifting from DMD to BMD-like phenotype. Eteplirsen is a phosphorodiamidate morpholino oligomer able to restore the dystrophin frame of lecture in subjects carrying a deletion amendable of skipping of exon 51 (approximately $14 \%$ of DMD patients) [19, 20]. Similarly, Golodirsen induces skipping of exon 53 [21]. Instead, Ataluren is a small molecule able to bypass dystrophin stop codon mutations by a read-through mechanism, allowing the expression of the protein [22].

Other strategies have been proposed to modify the course of the disease. For example, gene therapy delivers smaller forms of DYS with adeno-associated viral vector (AAV) and has been tested in clinical trials [23]. Genome editing through CRISPR-Cas9 technology has been attempted in animal models [24]. Epigenetic mechanisms can also be considered a therapeutic target. Post-transcriptional regulation could be implicated in the pathogenesis of the disease, as indicated by the extremely variable dystrophin expression (8-63\%) detected by analyzing BMD patients carrying the same mutation ( $\Delta 45-47)$ and comparable levels of dystrophin mRNA [25]. Moreover, several compounds target the pathological changes related to the loss of dystrophin and include corticosteroids, other anti-inflammatory drugs, antioxidants as Idebenone, vasodilators as Tadalafi and myostatin inhibitors [26].

In this context, non-coding RNAs (ncRNAs) have emerged as relevant molecules in the pathogenesis of several human disorders. Non-coding RNAs are not translated into proteins and originate from parts of codifying genes or are transcribed as independent genes. They can be classified according to their function as RNAs involved in translation (transfer RNA—tRNA, ribosomal RNA—rRNA), splicing (small nuclear RNA-snRNA), modifi of small RNAs (small nucleolar RNA—snoRNA), regulation of gene expression (piwi-associated RNA-piRNA, endogenous short-interfering RNA, microRNA-miRNA). Moreover, ultraconserved regions (T-UCR), large intergenic noncoding RNA (lincRNA), long noncoding RNA (lncRNAsmall interfering RNAs (siRNAs) and circular RNA have been described [27-29]. ncRNAs are involved in many different cellular pathways, including development and differentiation, tissue homeostasis, signal transduction and cell proliferation. They may also be identified in several biological fluids, like blood or urine, inside exosomes or linked to lipoproteins or freely circulating, thus representing extracellular biomarkers [27].

The most studied ncRNAs are represented by microRNAs, small RNA sequences (approximately 22 nucleotides) acting as post-transcriptional modifi MiRNAs repress target gene expression by binding the 3 ' untranscribed region ( $3^{\prime} \mathrm{UTR}$ ) of the corresponding mRNA with subsequent degradation or translation inhibition [31]. In certain conditions, they also improve gene expression, stabilizing the mRNA and facilitating its translation [32].

Long noncoding RNAs (lncRNAs) are molecules longer than 200 nucleotides, localized both in the nucleus and cytoplasm, encoded proximally to promoters of coding genes and poorly conserved across species [33]. They are implicated in diff ent cellular pathways, such as chromatin remodeling through histone methylation or acetylation or acting as a scaff for other enzymes, transcriptional activation or interference, cell traffi king, protein relocalization and phosphorylation or ubiquitination, mRNA processing and stability, splicing regulation and post-transcriptional and post-translational processes [34, 35]. LncRNAs can also be miRNAs precursors. Moreover, several types of noncoding RNAs, including lncRNAs and circular RNAs, are able to bind miRNAs, acting as 'sponges' and sequestering them from their targets [35-37].

Non-coding RNAs have been recently studied in dystrophinopathies to evaluate their role in the pathogenesis of the disease, as dystrophin expression modulators, as biomarkers and as possible therapeutic targets. This review will focus 
on the impact of miRNAs and lncRNAs on these aspects (Table 1).

\section{Modulators of dystrophin expression}

\section{Dystrophin expression in skeletal muscle can be directly modulated by specific miRNAs}

Fiorillo et al. analyzed muscle specimens of 10 BMD patients carrying a $D M D$ deletion 45-47. Subjects were divided into two groups, low-BMD and high-BMD, according to dystrophin levels by Western blot analysis (cut-off $20 \%$ ). Since protein expression was not directly related to dystrophin mRNA levels, muscle expression of specifi miRNAs binding dystrophin 3'UTR was studied. Selected miRNA levels were significantly overexpressed in low-BMD (miR-146b-5p, miR-382, miR-410, miR-758, miR-214, miR494, miR-223, miR-146a, miR-195, miR-374a, miR-103, miR-320a, let-7d, let-7a) and high-BMD subjects (miR-410, miR-758, miR-214, miR-223, miR-494). An inverse correlation between miRNA levels and protein expression was detected. Additionally, miR-31 was upregulated in DMD patients [25].

Likewise, animal models of dystrophinopathies showed an upregulation of miR-146b, miR-146a, miR-223 and miR-382 as detected in the vastus lateralis (50-fold, 3-fold, 8-fold) and sartorius (25-fold, 1.3-fold, 2.5-fold, 4-fold, respectively) of the Golden Retriever muscle dystrophy (GRMD) model. Similar upregulations were detected in the gastrocnemius muscle of the $m d x$ mouse. Moreover, a direct correlation between age and miRNA levels was found in GRMD (miR-146b, miR-146a, miR-223) and $m d x$ (miR-223, miR-31) models in comparison to wild-type controls [25].

Among the 14 miRNAs upregulated in the low-BMD group, Fiorillo identified 7 miRNAs inhibiting (miR-146b, miR-31, miR-374 and, to a lesser extent, miR-146a, miR223, miR-320a, miR-382) and 2 miRNAs enhancing dystrophin expression (miR-195, miR-758) [25]. Only limited knowledge of the actual muscular function of these miRNAs is available.

Furthermore, 14 lncRNAs originate from the DMD locus, most of them from intron regions close to dystrophin promoters or isoform-specifi fi t exons, since they are involved in the modulation of protein expression through targeting of their promoters. These transcripts localize to the nucleus and are expressed in at least one among skeletal muscle, heart, or brain. Transcription of these lncRNAs seems to be related to dystrophin and primed by myogenic diff entiation induced by MyoD. Their overexpression in human muscles and neuronal cells causes downregulation of brain and muscle dystrophin full-length isoforms (Dp427b and Dp427m) targeting the promoter; instead, Dp427p and
Dp71 transcription are barely affected. A negative correlation between lncRNAs and full-length DMD isoform levels has been found in dystrophinopathy female carriers [38].

\section{Pathogenesis of dystrophinopathies}

In addition to modulating dystrophin expression, miRNAs are involved in signaling pathways, development and cellular phenotype and regulation of myogenic proliferation and fibrosis.

Greco et al. suggested a classification of miRNAs involved in muscular pathways into miRNAs associated with 1) inflammation (miR-222, miR-223), expressed in response to muscle fiber damage; 2) degeneration (miR-1, miR-29c, miR-135a), reduced in the $m d x$ model or DMD patients or after ischemia and linked to myofi loss and fi osis; 3) regeneration (miR-31, miR-34c, miR-206, miR-335, miR449, miR-494), increased in the $m d x$ model, DMD patients and in response to induced ischemia [39].

Infl Fiorillo et al. further evaluated the role of miRNAs in the infl related to the dystrophic process. They treated $m d x$ myotubes with TNF-alpha and detected an increase in miR-146a and miR-223 levels. Since steroid therapy is one of the gold standards in DMD management, prednisolone was administered to reverse miRNA changes. Anti-infl ory drugs also decrease miR-146b and miR-382 levels. Therefore, they speculated that TNF-alpha-related inflammation might activate the NFkB pathway in muscle fi inducing miR-146a and miR-223 expression and inhibiting dystrophin expression [25]. Prednisolone administration decreases muscle levels of miRNAs related to infl (miR-142-5p, miR142-3p, miR-146a, miR-301a, miR-324-3p, miR-455-5p, miR-455-3p, miR-497, miR-652) up to normal values in the murine $m d x$ model [40] and affects serum expression of selected miRNAs (miR-206, miR-181a, miR-4538, miR4539, miR-606, miR-454) altered in young DMD patients [41]. Thus, another possible mechanism of action of corticosteroids may be related to serum miR-206 reduction, in which early overexpression negatively regulates target genes (RHGAP31, KHSRP, CORO1B, PTBP1, C7ORF58, DLG4, KLF4) worsening motor function in DMD [41]. Indeed, steroid treatment seems to further increase miR-1 and miR-133 levels in DMD, especially on a daily regimen compared to an intermittent one [42]. Moreover, miR-146 expression can be activated by NFkB and has a role in the immune system [43].

Fibrosis Another relevant feature of muscular dystrophies is collagen deposition. Studies on murine models identified miR-1 and miR-29 as being related to the TGF- $\beta$ pathway, fibrosis and myogenic differentiation.

Myoblast differentiation and myotube formation are promoted by miR-29 acting on Akt3, a serine/threonine protein 
Table 1 Role in skeletal muscle tissue and alteration of the most relevant miRNAs and lncRNAs in dystrophinopathies in muscle (M) and serum (S) samples of DMD or BMD patients or animal models

\begin{tabular}{|c|c|c|c|c|}
\hline ncRNA & Role in skeletal muscle & Dystrophinopathies & & References \\
\hline miR-1 & $\begin{array}{l}\text { Promote muscle differentiation } \\
\text { Role in FAP switch (S) } \\
\text { Degeneration }\end{array}$ & $\begin{array}{l}\text { Upregulated (S) } \\
\text { Downregulated (M) }\end{array}$ & $\mathrm{DMD} m d x$ & $\begin{array}{l}{[39,128-132]} \\
{[36]}\end{array}$ \\
\hline miR-21 & Promotes fibrosis & Upregulated (M) & $m d x$ & {$[46,47]$} \\
\hline miR-23a & Inhibits differentiation & Downregulated (U) & DMD & {$[73,142]$} \\
\hline miR-29 & $\begin{array}{l}\text { Decreases fibrosis } \\
\text { Promotes myoblast differentiation }\end{array}$ & Downregulated (M) & $m d x$ & {$[43]$} \\
\hline miR-31 & $\begin{array}{l}\text { Induced in ischemia damaged myofibers } \\
\text { Expressed in quiescent satellite cells } \\
\text { Dystrophin expression inhibitor } \\
\text { Delay muscle differentiation }\end{array}$ & $\begin{array}{l}\text { Upregulated (S) } \\
\text { Upregulated (M) }\end{array}$ & $\begin{array}{l}\mathrm{DMD} \\
m d x\end{array}$ & {$[23,39,65]$} \\
\hline miR-34c & $\begin{array}{l}\text { Regeneration } \\
\text { Induced in ischemia damaged myofibers }\end{array}$ & Upregulated (M) & $m d x$ & {$[36]$} \\
\hline miR-133a & $\begin{array}{l}\text { Promotes myoblasts proliferation } \\
\text { Role in FAP switch (S) }\end{array}$ & $\begin{array}{l}\text { Upregulated (S) } \\
\text { Downregulated (M) }\end{array}$ & $\begin{array}{l}\text { DMD } \\
\text { BMD }\end{array}$ & $\begin{array}{l}{[39,128-132]} \\
{[130]}\end{array}$ \\
\hline miR-133b & $\begin{array}{l}\text { Myoblast proliferation } \\
\text { Role in FAP switch (S) }\end{array}$ & Upregulated (S) & $\begin{array}{l}\text { DMD } \\
\text { BMD }\end{array}$ & $\begin{array}{l}{[39,128-132]} \\
{[130]}\end{array}$ \\
\hline miR-146a & $\begin{array}{l}\text { Promotes C2C12 myoblasts proliferation } \\
\text { Dystrophin expression inhibitor }\end{array}$ & Upregulated (M) & $m d x \mathrm{BMD}$ & {$[23]$} \\
\hline miR-146b & $\begin{array}{l}\text { Promotes myogenic differentiation } \\
\text { Dystrophin expression inhibitor }\end{array}$ & Upregulated (M) & $\begin{array}{l}m d x \\
\text { BMD }\end{array}$ & {$[23]$} \\
\hline miR-195 & Dystrophin expression enhancer & Upregulated (M) & BMD & {$[23]$} \\
\hline miR-199a & $\begin{array}{l}\text { Promotes fibrosis } \\
\text { Proliferation and differentiation (WNT pathway) }\end{array}$ & Upregulated (M) & DMD & [48] \\
\hline miR-206 & $\begin{array}{l}\text { Regeneration after muscle damage (expressed in proliferating myoblasts) } \\
\text { Activation of satellite cells } \\
\text { Promotes muscle differentiation } \\
\text { Role in FAP switch (S) }\end{array}$ & $\begin{array}{l}\text { Upregulated (S) } \\
\text { Upregulated (M) }\end{array}$ & $\begin{array}{l}\text { DMD } \\
\text { BMD } \\
m d x\end{array}$ & $\begin{array}{l}{[39,128-132]} \\
{[130]} \\
{[36]}\end{array}$ \\
\hline miR-208b & Myostatin related & Upregulated (S) & DMD & [131] \\
\hline miR-221 & $\begin{array}{l}\text { Progression from myoblasts to myocytes (expressed in terminally differen- } \\
\text { tiated myoblasts) }\end{array}$ & Upregulated (M) & $\begin{array}{l}\text { DMD } \\
\text { BMD }\end{array}$ & [77] \\
\hline miR-222 & Inflammation & Upregulated (M) & GRMD & [55] \\
\hline miR-223 & $\begin{array}{l}\text { Inflammation } \\
\text { Dystrophin expression inhibitor }\end{array}$ & Upregulated (M) & $\begin{array}{l}m d x \\
\text { BMD }\end{array}$ & [23] \\
\hline miR-320a & Dystrophin expression inhibitor & Upregulated (M) & BMD & {$[23]$} \\
\hline miR-374a & Dystrophin expression inhibitor & Upregulated (M) & BMD & {$[23]$} \\
\hline miR-382 & Dystrophin expression inhibitor & Upregulated (M) & $\begin{array}{l}m d x \\
\mathrm{BMD}\end{array}$ & [23] \\
\hline miR-486 & $\begin{array}{l}\text { Muscle growth and apoptosis } \\
\text { Promotes differentiation }\end{array}$ & Downregulated (M) & GRMD & {$[55]$} \\
\hline miR-494 & Regeneration & Upregulated (M) & $m d x$ & {$[23]$} \\
\hline miR-499 & Mithocondrial function & Upregulated (S) & DMD & {$[131]$} \\
\hline miR-758 & Dystrophin expression enhancer & Upregulated (M) & BMD & {$[23]$} \\
\hline SRA & Muscle differentiation & Downregulated (M) & $m d x$ & {$[81,98]$} \\
\hline RAM & Activation of myogenesis & ? & ? & {$[90]$} \\
\hline Dum & Myoblasts differentiation & ? & ? & {$[86]$} \\
\hline YY1 & $\begin{array}{l}\text { Myogenic differentiation } \\
\text { Promotes muscle regeneration }\end{array}$ & ? & ? & [89] \\
\hline Lnc-31 & Counteracts differentiation & Upregulated (M) & $m d x$ DMD & {$[96]$} \\
\hline Lnc-MD1 & Muscle differentiation and regeneration & $\begin{array}{l}\text { Upregulated (M) } \\
\text { Downregulated (M) }\end{array}$ & $\begin{array}{l}m d x \\
\mathrm{DMD}\end{array}$ & {$[95,98]$} \\
\hline Lnc-mg & Increase IGF2 & ? & $?$ & [93] \\
\hline
\end{tabular}


kinase responsive to growth factor cell signaling [44], and NFkB/Yin Yang 1 (YY1) [45] pathways. Moreover, miR-29 targets transcripts of fibrotic genes (for example, COL3A1, $F B N 1, Y Y 1, C O L 1 A 1)$ and is downregulated in the muscle of $m d x$ mice, to some extent due to TGF- $\beta$-mediated negative regulation. The loss of miR-29 in myoblasts promotes their differentiation in myofibroblasts and increases fibrosis [46].

MiR-1, expressed in adult skeletal and cardiac muscle tissue, promotes muscle diff entiation targeting HDAC4, which in turn inhibits skeletal muscle gene expression [47]. HDAC2, increased in DMD, represses both miR-1 and miR29 expression in $m d x$ mice; indeed, enhancing nuclear sphingolipid sphingosine-1-phosphate (S1P) inhibits HDAC in the $m d x$ mice muscles, increasing miR-1 and miR-29 and reducing fibrosis [48].

Another miRNA implicated in skeletal muscle fibrosis is miR-21, which has been found to be increased in a dystrophic mouse model and DMD fibroblasts. MiR-21 targets $P T E N$ and SPRY-1 genes. Its levels positively correlate with COL1A1 and COL6A1 transcript levels, and it is regulated by the extracellular proteolytic inhibitor PAI-1 and enhanced by TGF- $\beta$. Muscle fibroblasts of the dystrophic mouse model present an imbalance between PAI-1 and urokinase-type plasminogen activator (uPA), favoring the activation of TGF- $\beta$ and miR-21 expression. In $m d x$ mice, muscle fibrosis is anticipated by the loss of PAI- 1 or the overexpression of miR-21, while it is reduced by miR-21 inhibition [49, 50]. Furthermore, the fibrotic response is promoted by exosomes containing miR-199a-5p produced by DMD muscle fi oblasts [51].

Recent studies have highlighted the role of fibro-adipogenic progenitors (FAPs) in the pathogenesis of DMD, supporting regeneration during the early stage of the disease and fibro-fatty replacement in the late phase. Experiments on the murine $m d x$ model demonstrated that histone deacetylase inhibitors (HDACi) promote muscle cell regeneration and prevent connective substitution only if administered in earlier stages, facilitating the myogenic phenotype. Instead, in the late stage of the disease, the fibro-adipogenic phenotype of FAPs prevails. Selected myomiRs (miR-1, miR-133, miR206), induced by HDACi, seem to be implicated, through BAF60a and BAF60b, in the switch between fi o-adipogenic and myogenic phenotype of FAPs [52, 53].

Nitric oxide pathway The absence of dystrophin also brings about delocalization and reduction of nitric oxide synthase (nNOS) levels, leading to increased muscle fatigability. NO is responsible for the S-nitrosylation and chromatin association of HDAC2, which results in increased activity in $m d x$ mice. As previously stated, altered HDAC2 modifies the expression of fibrosis-related miRNAs (miR-1 and miR-29), while miR-206 is not aff since it is expressed in activated satellite cells [54]. Analysis of 617 $\operatorname{BMD}(\Delta 45-55)$ muscular biopsies revealed overexpression of miR-31, miR-708 and miR-34c interacting negatively with nNOS; in DMD myoblasts, inhibition of miR-708 and miR-34c increased nNOS expression, confirming their role in nNOS modulation [55]. Moreover, nitric oxide upregulates miR-27b, and decreasing peroxisome proliferatoractivated receptor gamma expression, inhibits the diff entiation of FAPs into adipocytes [56].

Disruption of the DAPC Dystrophinopathies may also have a secondary defi of the other components of the dystrophin-glycoprotein complex. De Arcangelis et al. suggested the role of the overexpression of miR-222 in this phenomenon, since it binds $\beta 1$-syntrophin 3'UTR in the $m d x$ mouse skeletal muscle with consequent downregulation of this protein [57]. To support this hypothesis, Robriquet et al. demonstrated that miR-222 and miR-486 are upregulated in newly regenerated muscle fi of GRMD dogs [58].

Myogenesis Muscle fi originate from mesodermic myogenic committed progenitors, expressing Pax3 and Pax7 and turn into myoblasts that proliferate, diff entiate and fuse into mononucleated myocytes and then multinucleated myotubes. A subpopulation forms the skeletal muscle satellite cells (SCs), mononucleated cells localized between the sarcolemma and basal lamina of muscle fibers, that remain quiescent in the adult muscle, but are able to activate and proliferate in response to muscle injury [59]. Pax7 is fundamental for the maintenance and proliferation of SCs and is repressed with the progression of myogenesis [60]. Both embryonal and adult myogenesis depends on the expression of myogenic regulatory factors (MRFs-MyoD, Myf5, myogenin and MRF4) and the interaction between each other. The myogenic determination factor 1 (MyoD) and myogenic factor 5 (Myf5) are expressed in early stages and involved in commitment and proliferation of the myogenic directed cells, while myogenin and herculin (MRF4) induce the terminal differentiation of committed cells with the subsequent fusion of myocytes and formation of myotubes. However, even MyoD can be involved in the regulation of terminal differentiation, and MRF4 also has a role in the early commitment stage. Moreover, myocyte enhancer factor 2 (MEF2) proteins are able to positively regulate different MRFs. Other factors involved in the regulation of myogenesis are HGF, FGFs, IGF-1 splice variants, myostatin, BMP4, Wnt proteins, Six1, Six4 and TGF- $\beta$. [61-64]. The complex process of myogenesis and the role of MRFs and ncRNAs in this process is represented in greater detail in Fig. 1.

MiRNAs are involved in the regulation of myogenesis, reciprocally interacting with myogenic transcription factors such as Pax3/7, Myf5, MyoD, myogenin, MRF4, MEF2 and SRF [65, 66]. Muscle-specifi lncRNAs are mainly expressed during myoblast differentiation and regulate transcription factors implicated in myogenesis, including MyoD and Myf5, as well [67]. 


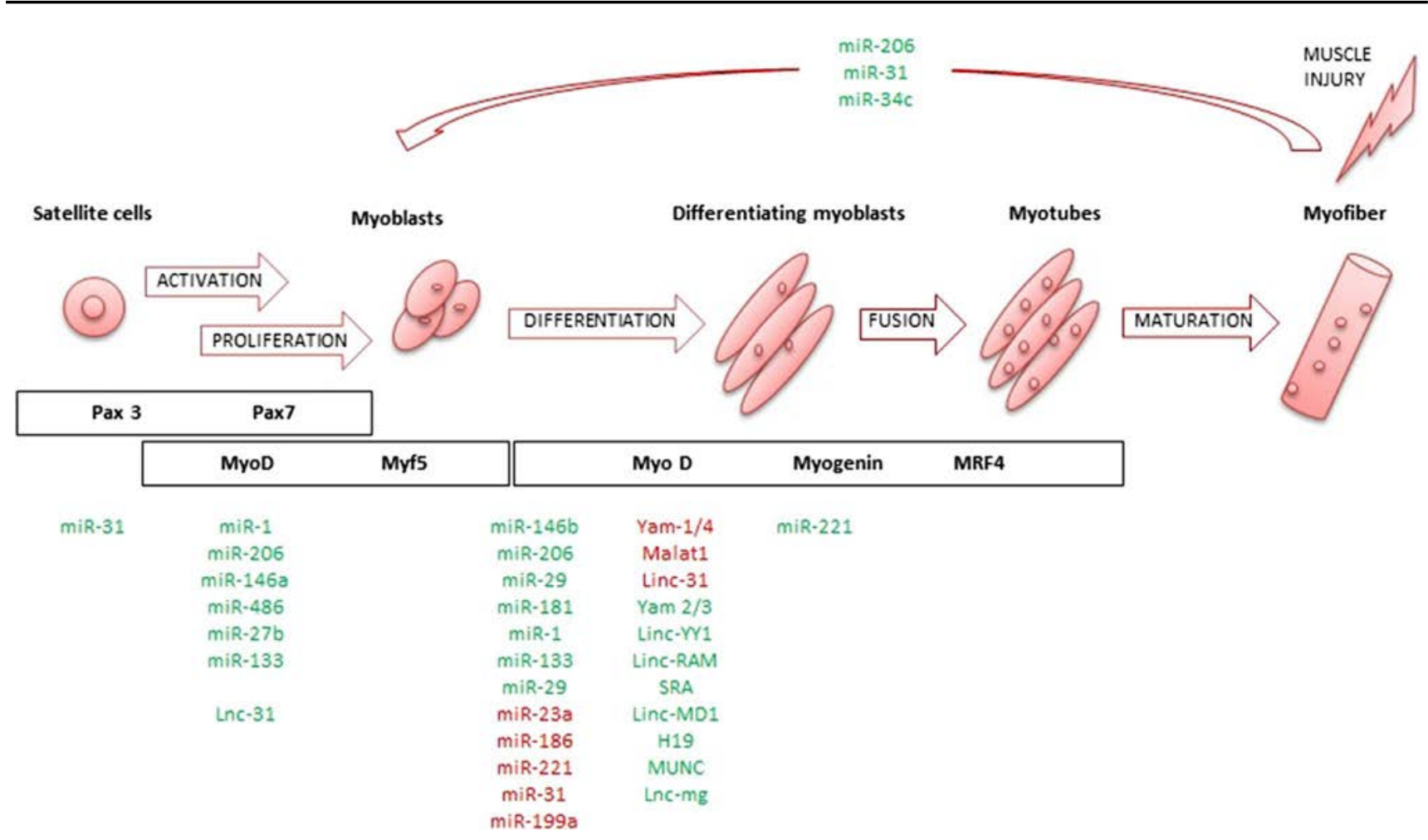

Fig. 1 Pax3 and Pax7 maintain satellite cells in a quiescence state by negatively regulating MyoD; miR-31 is involved in the maintenance of quiescence. Activation of muscle stem cells downregulates Pax3/7 so that Myf5 and MyoD are upregulated and involves several miRNAs. This leads to myoblast proliferation. After cell cycle exit, myo-

In satellite cells and regenerating myoblasts, miR-31 is highly expressed and seems to suppress the translation of transcripts for early myogenic factors targeting Myf5 and maintaining SCs in a quiescent state. DMD biopsies showed more elevated levels of miR-31 than healthy controls [68]. On the contrary, miR-1 and miR-206 facilitate the differentiation of SCs targeting Pax7 mRNA and thus blocking their proliferation [47]. Pax7 expression in SCs is also enhanced by a pathway involving tumor necrosis factor (TNF) receptor associated factor 6 (TRAF6) and c-JUN/activator protein 1 transcription factor. Lack of TRAF6 leads to overexpression of miR-1, miR-133 and miR-206 in cultured myogenic cells and subsequent too early diff entiation of SCs [69]. Also, miR-27b promotes SCs differentiation targeting Pax3 mRNA, and is induced at the beginning of the myogenic differentiation program [70].

Myoblast proliferation can be induced by miR-146a [71], miR-1, that targets HDAC4, and miR-133, which represses serum response factor (SRF) [47].

Other ncRNAs are involved in later stages of myogenesis. For instance, miR-146b [72] and miR-206 [73] promote myogenic differentiation targeting Smad Family Member 4 (Smad4) and Notch1 and p180 subunit of DNA polymerase alpha, respectively. Downregulation of miR-29, as reported genesis implies differentiation of myoblasts, fusion to form myotubes and maturation into myofibers. Other ncRNAs participate in response to muscle injury. In the scheme have been shown the main ncRNAs facilitating (green) or inhibiting (red) the various phases of myogenesis

in $m d x$ muscle, increases Ying Yang-1 (YY1) in C2C12 myoblasts, diminishing the differentiation of myoblasts into myotubes [74]. Furthermore, miR-181 increases terminal differentiation targeting the repressor Hox-A11 [75].

On the contrary, miR-23a inhibits myoblasts differentiation, acting on Myh1, Myh2 and Myh4 [76]. Mir-186 targets myogenin in differentiation myoblasts and is repressed during myogenic differentiation [77]. Diminished myoblast differentiation can also be induced by transforming growth factor (TGF) $\beta 1$ that represses miR-24, miR-29 and miR206 [78]. Even miR-221 participates in the progression from myoblasts to myocytes and its expression causes a delay in withdrawal from the cell cycle and the inhibition of sarcomeric protein accumulation in differentiating myoblasts [79]. MiR-221 is upregulated in DMD and BMD [80], suggesting a delay in the diff entiation process. Likewise, miR-31 is implicated in terminal differentiation, interacting with both Myf5 and dystrophin. While miR-31 levels tend to decrease at later stages of differentiation in wild-type mouse satellite cells, they are persistently upregulated in muscle tissue cultures of $m d x$ model [81] and DMD myoblasts [68], causing a delay in muscle differentiation. MiR-199a-3p targets IGF1/ AKT/mTOR pathway partially blocking myoblasts differentiation in C2C12 myoblasts [82]. 
Also, lncRNAs act during myoblasts diff entiation, as previously stated [67]. eRNAs $C E$ and $D R R$ regulate MyoD and myogenin, modifying the access to chromatin and the recruitment of RNAP II [83]. SRA lncRNA and its protein isoform SRAP facilitate MyoD activity in opposite ways, with an increase in the SRA/SRAP ratio during myogenesis and consequent activation of MyoD [84]. MyoD, in turn, controls H19, a lncRNA highly expressed during embryonic development that represses MyoD-inhibiting protein IGF2. H19 has a pro-myogenic role and promotes skeletal muscle differentiation and regeneration encoding miR-675-3p and miR-675-5p, which, respectively, repress a pathway mediated by bone morphogenetic protein (BMP) and the DNA replication initiation factor Cdc6 [85-87]. MyoD also targets Inc-AK143003 [88] and lcnRNA Dum [89]. Yam-1 (YY1associated muscle 1) and Yam-4 inhibit muscle differentiation, while Yam-2 and Yam-3 promote differentiation. Notably, Yam-1 reduces myomiRs expression during proliferation and represses myogenesis by activating miR-715 [90]. Deletion of Malat1 in $m d x$ mice improves muscle regeneration since it delays the switch between proliferative and differentiative phases of myogenesis; upon differentiation, miR-181a targets Malat1 for degradation, allowing MyoD activation [91]. Linc-YY1 promotes both myogenic differentiation and muscle regeneration [92]. Linc-RAM (linc-RNA activator of myogenesis) is upregulated during myogenesis and enhances transcription myogenic genes, including miR-206, by directly binding MyoD [93]. MUNC (MyoD upstream noncoding) favors myoblast differentiation by increasing MyoD, myogenin and Myh3 mRNA expression [94]. In contrast, Sirt1 AS IncRNA inhibits differentiation but promotes myoblast proliferation interacting with miR-34a [95]. Lnc-mg acts as a miR-125b sponge, increasing insulin-like growth factor 2 (IGF2), and its levels rise during myogenic differentiation. Lack of lnc-mg (myogenesis-associated lncRNA) results in muscle atrophy and loss of endurance in knockout mice, while its overexpression leads to muscle hypertrophy [96]. Muscle anabolic regulator 1 (MAR1) acts as a sponge for miR-487b regulating the myogenic regulator Wnt5 and its overexpression can increase muscle mass [97].

The expression of certain lncRNAs is altered in muscular dystrophies. In DMD myoblasts, Cesana et al. detected diminished levels of linc-MD1 that correlate with retardation of the muscle diff entiation program. In fact, lincMD1 binds miR-133 and miR-135, acting as a competing endogenous RNA for their mRNA targets, including the transcription factors MAML1 and MEF2C, which encode crucial myogenic factors. linc-MD1 administration appears to partially rescue the abnormal kinetics of differentiation in vitro [98]. Ballarino et al. identifi $\operatorname{lnc}-31$ as a lncRNA counteracting differentiation in proliferating myoblasts. Indeed, its expression is higher in those cells and is downregulated during diff entiation. Lnc-31 is also more abundant in $m d x$ muscles and DMD myoblasts due to a more intense regenerative activity; delay in the differentiation program in DMD myoblasts relates with less pronounced downregulation of $\operatorname{lnc}-31$. Notably, $\ln c-31$ originates from the precursor of miR-31 in an independent way [99].

Regeneration and response to myofi damage involve several miRNAs. For instance, miR-1, miR-133 and miR206 accelerate muscle regeneration, if injected in mouse models of muscle injury, inducing MyoD, myogenin and Pax7 [100]. Butchart et al. demonstrated a dysregulation of certain ncRNAs in $m d x$ mice compared to C57 mice. During the pre-necrotic phase, at 2 weeks, Meg3 and lncRNA SRA levels were lower, while miR-206 muscle levels were higher in $m d x$ mice. On the other hand, during the necrosis and regeneration stage, spanning from 4 to 6 weeks, linc-MD1 levels markedly increased instead of decreasing, while miR-1, miR-133a and Neat1_v2 levels were lower than C57 mice [101].

Other miRNAs involved in myogenesis include miR26a, regulating SMAD transcription factors, miR-221, miR-222, miR-322, miR-424 and miR-503, controlling cell-cycle regulators [65].

Cell signaling Even more signaling pathways implicate miRNA control. Ngheim et al. suggested that the upregulation of myostatin-related miRNAs (miR-539 and miR208b) might play a role in hypertrophy and functional sparing of the cranial sartorius in GRMD [102].

MiR-486 is another muscular miRNA that facilitates myogenic differentiation, notably reduced in $m d x$ mice and DMD patient muscles, whose overexpression improved performance and integrity of the sarcolemma, increased fi size and reduced nuclear centralization in $m d x$ mice. One of the miR-486 targets in skeletal muscle is DOCK3, which is induced in dystrophic muscles and modulates the PTEN/AKT (phosphatase and tensin homolog deleted on chromosome 10/ankyrin1) signaling pathway, consequently regulating muscle growth and apoptosis [103, 104].

Myogenic regulatory factors of the WNT signaling pathway, involving cell proliferation and differentiation (FZD4, JAG1, WNT2), are targeted by miR-199a-5p. It is regulated in a serum response factor (SRF)-dependent manner and is overexpressed in animal models and human dystrophic muscle, causing myofi disruption and sarcolemmal detachment [105].

Another signaling pathway coupling mitochondrial function and muscle fi type is mediated by miR-499. This miRNA inhibits Fnip1 reactivating a pathway mediated by AMP-activated protein kinase (AMPK) and PGC-1a; restoration of miR-499 in the $m d x$ mouse model lessens DMD severity [106]. 
Other miRNAs involved in various muscle regeneration and secondary response pathways have been found to be dysregulated in DMD muscle samples by Eisenberg et al. [80].

Other pathways Another subset of IncRNAs (Bvht and Fendrr) is also implicated in cardiomyocyte differentiation [107]. Cardiac muscle in dystrophinopathies presented a diff ent pattern of miRNA expression. For example, miR-448-3p downregulation is related to cellular oxidative stress [108] and miR340-5p expression to eccentric cardiac hypertrophy [109]. The miR-143/B-dystrobrevin/synapsin I pathway is likely involved in neuronal diff entiation and, therefore, in brain involvement in dystrophinopathies [110]. Furthermore, IncRNA KUCG1, originating from chromosome $\mathrm{X}$, could be related to mental retardation seen in some DMD patients [111].

Micropeptides Novel micropeptides, molecules smaller than 100 aminoacids, involved in muscle functions, have been recently discovered originating from muscle-specific lncRNAs [112, 113], posing the basis for further investigations of their role in dystrophinopathies. Here, a quick overview among micropeptides so far known as involved in muscle functions. Myoregulin (MLN), one of the most abundant transmembrane microproteins in adult skeletal muscle, controls the activity of SERCA, a membrane pump controlling calcium-mediated muscle relaxation [114]. Dwarf Open Reading Frame (DWORF) is highly expressed in the murine heart and enhances SERCA pump activity interacting with the inhibitory peptides phospholamban, sarcolipin, and MLN [115]. Furthermore, it has been demonstrated that micropeptide in mitochondria (MPM) is downregulated in DMD patients. This micropeptide is localized in mitochondria and upregulated during C2C12 myoblasts differentiation and regeneration after cardiotoxin damage [116]. Mitoregulin (Mtln) is another molecule, encoded by LINC00116, localized in the mitochondrial membrane, that binds cardiolipin, participates in protein assembly processes and enhances respiratory efficiency [117]. Instead, LINC00961 encodes for a small regulatory polypeptide of aminoacid response (SPAR), a lysosomal protein involved in mTORC1 signaling pathway and, therefore, protein synthesis and cell growth [118]. Myomaker and Myomixer are other two molecules that regulate myoblasts or myocytes fusion [119]. At last, lncRNA-Six1 interact with muscle-related genes (MYOG, MYHC, MYOD, IGF1R, INSR) and is involved in muscle growth, since its overexpression induces Six1 gene expression, through repression of miR-1611, enhancing cell proliferation and division $[120,121]$.

\section{Serum biomarkers}

An abnormal serum expression of diff ent miRNAs has been associated with various oncological, neurodegenerative, cardiovascular, metabolic and hereditary diseases, suggesting a potential role as a minimally invasive biomarker [122]. MiRNAs selectively involved in muscular pathways and related to muscular dystrophies have been named dystromirs or myomiRs. They include miR-1, miR-133a, miR133b, miR-31 and miR-206 [123].

MiR-1 and miR-133a are expressed from the same transcript within the skeletal and cardiac muscle, but they have diff ent functions [80]. MiR-1 promotes myogenesis and terminal differentiation, acting on HDAC4 and connexin-43, while miR-133 enhances myoblast proliferation [47]. Mi-206 and miR-133b are also codified by the same ncRNA. MiR206 is specifi to skeletal muscle, particularly oxidative fi and is expressed in proliferating myoblasts under negative regulation of TGF- $\beta$ and myostatin and positive of MyoD and myogenin. MiR-206 promotes regeneration after muscle damage through differentiation and fusion of myotube progenitors, partially through HDAC4 inhibition; in fact, newly formed muscle fibers from satellite cells during regeneration in CTX-injured and dystrophic $m d x$ muscles presented high expression of miR-206; the lack of this in CXMDJ muscles might be related to the potential of muscle regeneration. Moreover, miR-206 has a role in muscle hypertrophy and atrophy and suppresses utrophin, while its overexpression causes upregulation of utrophin levels in dystrophic conditions and decreases proinflammatory cytokines and macrophagic infi ation in $m d x$ mouse muscle [124-128].

At fi $\mathrm{t}$, it was assumed that myomiRs were passively released from damaged muscle fibers into the bloodstream after necrosis or sarcolemmal dysfunction. However, muscle levels of miRNAs do not always correspond to a proportional change of miRNA muscle levels in serum. Therefore, more complex mechanisms have been postulated, such as abnormal secretion due to dystrophin deficiency or selective release during muscle differentiation and regeneration [129]. Moreover, extracellular myomiRs seem to be predominantly non-vescicular [130].

A substantial increase in miR-1, miR-133a, miR-133b, and miR-206 has been demonstrated in the serum of patients with Duchenne muscular dystrophy [42, 131-135]. Discordant results involve serum levels of miR-31 in DMD since it has been found to be slightly increased by Zaharieva et al. [42] and decreased by Vigner [131].

A straightforward relationship with clinical features and disease progression has not yet been found. A few studies indicated an inverse correlation between serum levels of miR-1, miR-133 and miR-206 in ambulant DMD patients and disease severity evaluated through the Medical Research Council (MRC) scale, temporized tests [132] or North Star Ambulatory Assessment (NSAA) scale [133]. Instead, Zaharieva et al. found lower dystromir levels in the serum of patients having lost ambulation compared to ambulant subjects and subjects requiring scoliosis surgery or having 
low forced vital capacity (FVC) values; no significant correlation with the NSAA score was reported [42]. These discrepancies may be partially explained by the different study populations analyzed regarding clinical severity and age. In fact, Cacchiarelli et al. evaluated patients from 3 to 6 years of age [133], Vignier et al. over 3 year-old [131], Zaharieva et al. ambulant DMD subjects between 4 and 13 years old [42]. Even the relationship with age differs in the various studies, either as being absent [132] or directly [133, 134] or inversely proportional [42] to serum levels. In one report, a considerable decrease in the amount of miR-133a, miR-133b, miR-31 and miR-1 was detected after the age of 11 years [42].

Furthermore, Zaharieva et al. found higher levels of miR1, miR-31 and miR-133b in patients on a daily steroid regimen compared to intermittent regimen or absence of steroid treatment, suggesting a correlation between the anabolic effect of corticosteroids, increased muscle mass in subjects treated with higher steroids doses and circulating miRNAs levels [42].

Likewise, patients affected by BMD still present a mild increase in serum levels of miR-206, miR-1 and miR-133 in comparison to healthy controls, even if they are lower than in DMD [133]. Similar fi ngs have been described by Matsuzaka et al. [135] and Li et al. [134], but without statistical significance, in a group of patients between 5 and 31 years and 1 and 14 years, respectively. Patients studied by $\mathrm{Li}$ et al. were not on steroids. However, Zaharieva did not observe any difference in dystromir serum levels compared to controls, except for a slight increase in miR-206 [42].

Serum miR-206 is raised even in female carriers of dystrophinopathies [136]. Mouse $m d x[131,137]$ and canine $\mathrm{X}$-linked muscular dystrophy $\left(\mathrm{CXMD}_{\mathrm{J}}\right)$ models [138] showed overexpression of serum miR-1, miR-133a and miR-206.

Muscle levels of myomiRs can actually be unchanged or mildly increased or even decreased. For instance, Zaharieva showed that miR-1 is downregulated, while miR-206, miR-133a and miR-133b do not show signifi changes, confirming that serum levels are the result of more complex molecular mechanisms than passive release [42]. Moreover, miR-1 and miR-133 are abundant in mature muscle fibers but reduced in human and murine dystrophic myoblasts [54], while miR-206 is upregulated in skeletal muscles of 8 weeks old $m d x$ mouse [137]. Deng et al. obtained muscle samples from a 1-month-old $m d x$ mice highlighting overexpression of miR-1, miR-133a and miR-206 [139].

Thus, some authors suggested using miR-206 as a marker of muscle regeneration, considering that it is expressed in satellite cells and proliferating myoblasts and it decreases with age in muscle controls, and miR-1 and miR-133 are markers of residual muscle mass and decrease with age [42, 133, 134]. Extracellular myomiR levels can also be influenced by other factors, such as total muscle mass, exercise, muscle regeneration, immobilization and age [129, 140]. An increase in serum levels of miR-1, miR-133a and miR-206 was detected after muscle damage induced by CTX in mice [135]. Moreover, Gomes et al. demonstrated an increase in dystromir serum levels as a result of exercise in healthy subjects [141].

Other serum miRNAs altered in dystrophinopathies include miR-499, miR-208a, miR-208b [134], miR-30c, miR-181a [142], miR-378 [131], miR-95, miR-539 [143], miR-22 and miR-193b [144].

MiRNAs have been quantified even in different biological $\mathrm{fl}$ ids. The urine of 54 Duchenne muscular dystrophy patients displayed downregulation of miR-29c-3p (ambulant subjects), miR-23b-3p and miR-21-5p (nonambulant subjects) compared to healthy controls [145].

Structural cardiac alteration indicative of myocardial fibrosis correlates with serum increases of miR-222, miR26a and miR-378a-5p [146]. Other miRNAs related to cardiomyopathy are miR-208a, miR-208b and miR-499, expressed mainly in cardiac muscle and slow skeletal muscle [134, 143].

\section{Tool for therapy efficacy evaluation}

Currently, several molecular approaches have been developed to treat dystrophinopathies. Most of the current clinical trials employ functional tests, such as the Six Minute Walking Distance or Motor Function Measure Scale, as an outcome measure. Unfortunately, a signifi change in functional clinical outcomes requires long treatment times.

Several potential biomarkers have been suggested, concerning myonecrosis, regeneration, inflammation, fibrosis, oxidative stress, both using histological analysis (i.e. albumin levels related to sarcolemmal leakiness, embryonic or neonatal myosins, central myonuclei, infl ory infi trates) and serum or urine levels of different metabolites (i.e. CK, aldolase, fi $\quad$ C, myosin light chain, serum TNF) [147]. Changes in miRNA levels in muscle specimens or serum could be a promising and non-invasive tool to evaluate the efficacy of novel treatments on dystrophin expression, muscle damage and inflammation.

So far, the majority of these analyses was performed investigating exon skipping effects. Studies on the $m d x$ murine model demonstrated an almost complete normalization of increased miR-1 and miR-206 serum levels (previously 20-40-fold compared to wild type), proportional to dystrophin restoration, after 1 month from the administration of exon 23 skipping treatment through adeno-associated virus (AAV) vectors [133]. Similar, but not statistically significant, myomir modifications were detected in the serum of DMD patients treated for 12 weeks with a novel morpholino 
antisense oligomer inducing exon 51 skipping (Eteplirsen) [42]. Moreover, correct nNOS localization after exon 45 skipping in DMD myoblasts normalizes miR-1 and miR29c expression [148]. In the $m d x$ mouse, an increase in dystrophin levels after exon 23 skipping through endovenous morpholino administration corresponds to reduced levels of selected miRNAs in the anterior tibial muscle (miR-146a, miR-374a, miR-223, miR-320a, miR-382) but not in diaphragm or gastrocnemius muscles [26]. Also, Cacchiarelli et al. demonstrated how exon 23 skipping using AAV vectors in $m d x$ mice resulted in normalization of downregulated miRNA (miR-1, miR-133, miR-29c, miR-30c), increase in miR-206 and reduction in miR-223 in muscle samples [54]. Roberts et al. showed normalization of serum miR-1, miR133a and miR-206 after morpholino-mediated dystrophin restoration in $m d x$ mice, proportional to the degree of protein rescue $[137,144]$. Further studies found restoration towards wild-type levels of miR-21, miR-29c and miR-146b in $m d x$ mouse muscles treated with exon skipping, but not of the upregulated miR-31, miR-34c and miR-206 [149].

A reduction in miR-31 levels, linked to dystrophin restoration, was observed after CRISPR/Cas9 treatment of myotubes derived from induced pluripotent stem cells (iPSCs) of DMD subjects [150].

\section{Potential therapeutic targets}

As shown by the following preliminary experiments, modulation of miRNA levels may be used as support for other innovative treatments.

One of the most consistently reported miRNAs involved in dystrophin expression is miR-31, which represses $D M D$ expression targeting the $3^{\prime} \mathrm{UTR}$ region. MiR-31 showed a 50 -fold enrichment compared with the control in $m d x$ mouse muscle. Cacchiarelli et al. attempted exon 51 skipping in human DMD myoblasts using antisense sequences administered through lentivirus: concomitant inhibition of miR-31, though a specifi sponge construct, improved dystrophin restoration leading to dystrophin levels greater than those achieved by exon skipping alone [68]. Analogous studies were performed by Hildyard et al. injecting both exon skipping and miR31-modulating oligonucleotides in the tibialis anterior muscle of the $m d x$ mouse. While their results were promising in cell culture models, several problems arose in vivo, since the two oligonucleotides competed with each other for myofi entry and intravenous delivery of skipping morpholino resulted in fatalities [151].

Supplementation of miR-29c, which is involved in muscle fibrosis, through the AAV vector in the gastrocnemius of the $m d x$ mouse, leads to muscular connective tissue decrease and weakness improvement. Almost complete normalization of muscle strength has been obtained with the combined administration of miR-29c and microdystrophin [152]. Wang et al. detected an increase in the number of regenerating fibers after injection of oligonucleotides mimicking miR-29c in the tibialis anterior muscles of $m d x$ mice [46].

Local injection of a mixture of miRNAs (miR-1, miR133, miR-206) in a rat skeletal muscle injury model enhances muscle regeneration [100]. In contrast, Bulaklak et al. showed improved motor function in $m d x$ mice after AAV-mediated administration of a miR-206 decoy target [153].

Utrophin is a protein analogue to dystrophin, able to partially compensate in its absence. This compensatory mechanism differs in mice and humans, due to differential regulation of Utrn isoforms, and provide a major protective effect in $m d x$ mouse model, responsible for the milder phenotype compared to DMD patients [154]. Utrophin expression can be downregulated by miR-206, miR-150, miR-196b, miR-296-5p, miR-133b and let-7c; blocking those miRNAs resulted in increased levels of utrophin in C2C12 cells [155]. Blocking the interaction between let-7c and utrophin 3'UTR through oligonucleotides brings about utrophin upregulation and improvement of the dystrophic phenotype in the $m d x$ mouse model [156].

Other noncoding RNAs may be employed for therapeutic purposes: U1 snRNA-derived antisense molecules induce exon 45 skipping in $\Delta 44$ human DMD myoblasts, relocalizing nNOS and recovering the normal expression of myogenic markers and selected miRNAs [148].

Last, Aminzadeh et al. developed an approach based on cardiosphere-derived cells (CDCs) injected into the hearts of $m d x$ mice to improve survival and ambulatory capacity due to the secretion of exosomes able to increase dystrophin expression through miR-148a [157].

\section{Perspectivesand conclusions}

Serum creatine kinase (CK) levels, an enzyme released by damaged muscle fi are elevated in the early stages of these muscular dystrophies and gradually decrease later on. Due to their $\mathrm{fl} \quad$ they do not represent a precise blood biomarker for evaluating disease progression and clinical worsening or improvement. MiRNAs seem to be more stable than CKs and are correlated to clinical severity in some cases, suggesting a potential role as serum biomarker even in clinical trials, especially miR-1, miR-133 and miR206. Further studies are needed to refi and standardize miRNA quantification on serum [158], and we should keep in mind that serum levels of myomiRs may increase both for muscle mass reduction and function improvement, as well as decrease both for physical activity and muscle mass increase [129]. 
Moreover, the analysis of miRNA expression may improve our knowledge of the pathogenesis of dystrophinopathies and the pathways upon which the drugs act. Different miRNA expression could also explain the different phenotype and dystrophin levels highlighted in BMD patients carrying the same deletion, since some of them are capable of dystrophin expression inhibition, as miR-31 in DMD patients.

MiRNAs can also be useful for monitoring the effi through serum or muscle changes, as reported mainly in studies involving exon skipping approaches. Furthermore, their administration may enhance the effects of known therapies, as shown with the administration of miR-31 modulating agents in addition to exon skipping, and improve pathological aspects of the disease, such as inflammation or fibrosis, as reported by Heller et al. with the supplementation of miR-29 and microdystrophin in $m d x$ mice [152].

In conclusion, miRNAs have been demonstrated to be an interesting research field in dystrophinopathies, regarding pathogenesis, progression of the disease and treatment. While little is yet known, the increasing discoveries related to roles of lncRNAs in muscle functions and their interaction with miRNAs, are likely to provide further insights for dystrophinopathies.

Acknowledgements We gratefully thank the Associazione Centro Dino Ferrari for its support.

Author contributions RB, FM and SC conceived and wrote the manuscript, NB and GPC revised the text.

Funding The project received partial support from Italian Ministry of Health to GPC.

\section{References}

1. Emery AE (1991) Population frequencies of inherited neuromuscular diseases - a world survey. Neuromuscul Disord NMD 1:19-29

2. Mah JK, Korngut L, Dykeman J et al (2014) A systematic review and meta-analysis on the epidemiology of Duchenne and Becker muscular dystrophy. Neuromuscul Disord NMD 24:482-491. https://doi.org/10.1016/j.nmd.2014.03.008

3. Monaco AP, Bertelson CJ, Liechti-Gallati S et al (1988) An explanation for the phenotypic differences between patients bearing partial deletions of the DMD locus. Genomics 2:90-95

4. Gao QQ, McNally EM (2015) The dystrophin complex: structure, function, and implications for therapy. Compr Physiol 5:12231239. https://doi.org/10.1002/cphy.c140048

5. Petrof BJ, Shrager JB, Stedman HH et al (1993) Dystrophin protects the sarcolemma from stresses developed during muscle contraction. Proc Natl Acad Sci 90:3710-3714. https://doi. org/10.1073/pnas.90.8.3710

6. Fairclough RJ, Perkins KJ, Davies KE (2012) Pharmacologically targeting the primary defect and downstream pathology in Duchenne muscular dystrophy. Curr Gene Ther 12:206-244. https:// doi.org/10.2174/156652312800840595
7. Boldrin L, Zammit PS, Morgan JE (2015) Satellite cells from dystrophic muscle retain regenerative capacity. Stem Cell Res 14:20-29. https://doi.org/10.1016/j.scr.2014.10.007

8. Cohn RD, Campbell KP (2000) Molecular basis of muscular dystrophies. Muscle Nerve 23:1456-1471. https ://doi.org/10.1002/1097-4598(20001 0$) 23: 10 \% 3 c 145$ 6:AID-MUS2\%3e3.0.CO;2-T

9. Nichols B, Takeda S, Yokota T (2015) Nonmechanical roles of dystrophin and associated proteins in exercise, neuromuscular junctions, and brains. Brain Sci 5:275-298. https://doi. org/10.3390/brainsci5030275

10. Constantin B (2014) Dystrophin complex functions as a scaffold for signalling proteins. Biochim Biophys Acta BBA Biomembr 1838:635-642. https://doi.org/10.1016/j.bbamem.2013.08.023

11. Darras BT, Urion DK, Ghosh PS (1993) Dystrophinopathies. In: Adam MP, Ardinger HH, Pagon RA, et al (eds) GeneReviews ${ }^{\circledR}$. University of Washington, Seattle, Seattle

12. Sussman M (2002) Duchenne muscular dystrophy. J Am Acad Orthop Surg 10:138-151

13. Brandsema JF, Darras BT (2015) Dystrophinopathies. Semin Neurol 35:369-384. https://doi.org/10.1055/s-0035-1558982

14. Nigro G, Comi LI, Politano L, Bain RJ (1990) The incidence and evolution of cardiomyopathy in Duchenne muscular dystrophy. Int J Cardiol 26:271-277

15. Magri F, Govoni A, D’Angelo MG et al (2011) Genotype and phenotype characterization in a large dystrophinopathic cohort with extended follow-up. J Neurol 258:1610-1623. https://doi. org/10.1007/s00415-011-5979-z

16. Yazaki M, Yoshida K, Nakamura A et al (1999) Clinical characteristics of aged Becker muscular dystrophy patients with onset after 30 years. Eur Neurol 42:145-149. https://doi. org/10.1159/000008089

17. Nigro G, Comi LI, Politano L et al (1995) Evaluation of the cardiomyopathy in Becker muscular dystrophy. Muscle Nerve 18:283-291. https://doi.org/10.1002/mus.880180304

18. Govoni A, Magri F, Brajkovic S et al (2013) Ongoing therapeutic trials and outcome measures for Duchenne muscular dystrophy. Cell Mol Life Sci CMLS 70:4585-4602. https://doi.org/10.1007/ s00018-013-1396-z

19. Mendell JR, Goemans N, Lowes LP et al (2016) Longitudinal eff of eteplirsen versus historical control on ambulation in Duchenne muscular dystrophy. Ann Neurol 79:257-271. https ://doi.org/10.1002/ana.24555

20. Lim KRQ, Maruyama R, Yokota T (2017) Eteplirsen in the treatment of Duchenne muscular dystrophy. Drug Des Devel Ther 11:533-545. https://doi.org/10.2147/DDDT.S97635

21. Heo Y-A (2020) Golodirsen: first approval. Drugs 80:329-333. https://doi.org/10.1007/s40265-020-01267-2

22. Bushby K, Finkel R, Wong B et al (2014) Ataluren treatment of patients with nonsense mutation dystrophinopathy: ataluren for dystrophinopathy. Muscle Nerve 50:477-487. https://doi. org/10.1002/mus.24332

23. Duan D (2018) Systemic AAV micro-dystrophin gene therapy for duchenne muscular dystrophy. Mol Ther J Am Soc Gene Ther 26:2337-2356. https://doi.org/10.1016/j.ymthe.2018.07.011

24. Matre PR, Mu X, Wu J et al (2019) CRISPR/Cas9-based dystrophin restoration reveals a novel role for dystrophin in bioenergetics and stress resistance of muscle progenitors. Stem Cells Dayt Ohio 37:1615-1628. https://doi.org/10.1002/stem.3094

25. Fiorillo AA, Heier CR, Novak JS et al (2015) TNF- $\alpha$-induced microRNAs control dystrophin expression in becker muscular dystrophy. Cell Rep 12:1678-1690. https://doi.org/10.1016/j. celrep.2015.07.066

26. Verhaart IEC, Aartsma-Rus A (2019) Therapeutic developments for Duchenne muscular dystrophy. Nat Rev Neurol 15:373-386. https://doi.org/10.1038/s41582-019-0203-3 
27. Mattick JS, Makunin IV (2006) Non-coding RNA. Hum Mol Genet 15 Spec No 1:R17-R29. https://doi.org/10.1093/hmg/ ddl046

28. Ma L, Bajic VB, Zhang Z (2013) On the classifi of long non-coding RNAs. RNA Biol 10:925-933. https://doi. org/10.4161/rna.24604

29. Hombach S, Kretz M (2016) Non-coding RNAs: classification, biology and functioning. Adv Exp Med Biol 937:3-17. https:// doi.org/10.1007/978-3-319-42059-2_1

30. Trzybulska D, Vergadi E (2018) MiRNA and other noncoding RNAs as promising diagnostic markers. EJIFCC 29(3):221-226

31. He L, Hannon GJ (2004) MicroRNAs: small RNAs with a big role in gene regulation. Nat Rev Genet 5:522-531. https://doi. org/10.1038/nrg1379

32. Valinezhad Orang A, Safaralizadeh R, Kazemzadeh-Bavili M (2014) Mechanisms of miRNA-mediated gene regulation from common downregulation to mRNA-specifi upregulation. Int J Genom. https://doi.org/10.1155/2014/970607

33. Bu D, Luo H, Jiao F et al (2015) Evolutionary annotation of conserved long non-coding RNAs in major mammalian species. Sci China Life Sci 58:787-798. https://doi.org/10.1007/ s11427-015-4881-9

34. Geisler S, Coller J (2013) RNA in unexpected places: long non-coding RNA functions in diverse cellular contexts. Nat Rev Mol Cell Biol 14:699-712. https://doi.org/10.1038/nrm36 79

35. Zhang X, Wang W, Zhu W et al (2019) Mechanisms and functions of long non-coding RNAs at multiple regulatory levels. Int J Mol Sci. https://doi.org/10.3390/ijms20225573

36. Bak RO, Mikkelsen JG (2014) miRNA sponges: soaking up miRNAs for regulation of gene expression. Wiley Interdiscip Rev RNA 5:317-333. https://doi.org/10.1002/wrna.1213

37. Paraskevopoulou MD, Hatzigeorgiou AG (2016) Analyzing MiRNA-LncRNA interactions. In: Feng Y, Zhang L (eds) Long non-coding RNAs: methods and protocols. Springer, New York, pp 271-286

38. Bovolenta M, Erriquez D, Valli E et al (2012) The DMD locus harbours multiple long non-coding RNAs which orchestrate and control transcription of muscle dystrophin mRNA isoforms. PLoS One 7:e45328. https://doi.org/10.1371/journal.pone.00453 28

39. Greco S, De Simone M, Colussi C et al (2009) Common microRNA signature in skeletal muscle damage and regeneration induced by Duchenne muscular dystrophy and acute ischemia. FASEB J 23:3335-3346. https://doi.org/10.1096/fj.08-128579

40. Fiorillo AA, Tully CB, Damsker JM et al (2018) Muscle miRNAome shows suppression of chronic inflammatory miRNAs with both prednisone and vamorolone. Physiol Genom 50:735745. https://doi.org/10.1152/physiolgenomics.00134.2017

41. Liu DZ, Stamova B, Hu S et al (2015) MicroRNA and mRNA expression changes in steroid naïve and steroid treated DMD patients. J Neuromuscul Dis 2:387-396. https://doi.org/10.3233/ JND-150076

42. Zaharieva IT, Calissano M, Scoto M et al (2013) Dystromirs as serum biomarkers for monitoring the disease severity in duchenne muscular dystrophy. PLoS One 8:e80263. https://doi. org/10.1371/journal.pone.0080263

43. Taganov KD, Boldin MP, Chang K-J, Baltimore D (2006) NFkappaB-dependent induction of microRNA miR-146, an inhibitor targeted to signaling proteins of innate immune responses. Proc Natl Acad Sci USA 103:12481-12486. https://doi.org/10.1073/ pnas.0605298103

44. Wei W, He H-B, Zhang W-Y et al (2013) miR-29 targets Akt3 to reduce proliferation and facilitate differentiation of myoblasts in skeletal muscle development. Cell Death Dis 4:e668. https://doi. org/10.1038/cddis.2013.184

45. Wang H, Garzon R, Sun H et al (2008) NF-kappaB-YY1-miR-29 regulatory circuitry in skeletal myogenesis and rhabdomyosarcoma. Cancer Cell 14:369-381. https://doi.org/10.1016/j. ccr.2008.10.006

46. Wang L, Zhou L, Jiang P et al (2012) Loss of miR-29 in myoblasts contributes to dystrophic muscle pathogenesis. Mol Ther 20:1222-1233. https://doi.org/10.1038/mt.2012.35

47. Chen J-F, Mandel EM, Thomson JM et al (2006) The role of microRNA-1 and microRNA-133 in skeletal muscle proliferation and diff entiation. Nat Genet 38:228-233. https://doi. org/10.1038/ng1725

48. Nguyen-Tran D-H, Hait NC, Sperber H et al (2014) Molecular mechanism of sphingosine-1-phosphate action in Duchenne muscular dystrophy. Dis Model Mech 7:41-54. https://doi. org/10.1242/dmm.013631

49. Ardite E, Perdiguero E, Vidal B et al (2012) PAI-1-regulated miR-21 defines a novel age-associated fibrogenic pathway in muscular dystrophy. J Cell Biol 196:163-175. https://doi. org/10.1083/jcb.201105013

50. Zanotti S, Gibertini S, Curcio M et al (2015) Opposing roles of miR-21 and miR-29 in the progression of fibrosis in Duchenne muscular dystrophy. Biochim Biophys Acta BBA Mol Basis Dis 1852:1451-1464. https://doi.org/10.1016/j.bbadis.2015.04.013

51. Zanotti S, Gibertini S, Blasevich F et al (2018) Exosomes and exosomal miRNAs from muscle-derived fi oblasts promote skeletal muscle fi osis. Matrix Biol 74:77-100. https://doi. org/10.1016/j.matbio.2018.07.003

52. Giordani L, Sandoná M, Rotini A et al (2014) Muscle-specific microRNAs as biomarkers of Duchenne Muscular Dystrophy progression and response to therapies. Rare Dis 2:e974969. https ://doi.org/10.4161/21675511.2014.974969

53. Saccone V, Consalvi S, Giordani L et al (2014) HDAC-regulated myomiRs control BAF60 variant exchange and direct the functional phenotype of fi o-adipogenic progenitors in dystrophic muscles. Genes Dev 28:841-857. https://doi.org/10.1101/ gad.234468.113

54. Cacchiarelli D, Martone J, Girardi E et al (2010) MicroRNAs involved in molecular circuitries relevant for the duchenne muscular dystrophy pathogenesis are controlled by the dystrophin/nNOS pathway. Cell Metab 12:341-351. https://doi. org/10.1016/j.cmet.2010.07.008

55. Guilbaud M, Gentil C, Peccate C et al (2018) miR-708-5p and miR-34c-5p are involved in nNOS regulation in dystrophic context. Skelet Muscle. https://doi.org/10.1186/s13395-018-0161-2

56. Cordani N, Pisa V, Pozzi L et al (2014) Nitric oxide controls fat deposition in dystrophic skeletal muscle by regulating fibroadipogenic precursor differentiation. Stem Cells Dayt Ohio 32:874-885. https://doi.org/10.1002/stem.1587

57. De Arcangelis V, Serra F, Cogoni C et al (2010) $\beta 1$-syntrophin modulation by miR-222 in mdx mice. PLoS One. https://doi. org/10.1371/journal.pone.0012098

58. Robriquet F, Babarit C, Larcher T et al (2016) Identification in GRMD dog muscle of critical miRNAs involved in pathophysiology and effects associated with MuStem cell transplantation. BMC Musculoskelet Disord. https://doi.org/10.1186/s1289 1-016-1060-5

59. Morgan JE, Partridge TA (2003) Muscle satellite cells. Int J Biochem Cell Biol 35:1151-1156. https://doi.org/10.1016/s1357 -2725(03)00042-6

60. von Maltzahn J, Jones AE, Parks RJ, Rudnicki MA (2013) Pax7 is critical for the normal function of satellite cells in adult skeletal muscle. Proc Natl Acad Sci USA 110:16474-16479. https ://doi.org/10.1073/pnas.1307680110 
61. Bentzinger CF, Wang YX, Rudnicki MA (2012) Building muscle: molecular regulation of myogenesis. Cold Spring Harb Perspect Biol. https://doi.org/10.1101/cshperspect.a008342

62. Buckingham M, Rigby PWJ (2014) Gene regulatory networks and transcriptional mechanisms that control myogenesis. Dev Cell 28:225-238. https://doi.org/10.1016/j.devcel.2013.12.020

63. Zammit PS (2017) Function of the myogenic regulatory factors Myf5, MyoD, Myogenin and MRF4 in skeletal muscle, satellite cells and regenerative myogenesis. Semin Cell Dev Biol 72:1932. https://doi.org/10.1016/j.semcdb.2017.11.011

64. Asfour HA, Allouh MZ, Said RS (2018) Myogenic regulatory factors: the orchestrators of myogenesis after 30 years of discovery. Exp Biol Med Maywood NJ 243:118-128. https://doi. org/10.1177/1535370217749494

65. Ballarino M, Morlando M, Fatica A, Bozzoni I (2016) Non-coding RNAs in muscle differentiation and musculoskeletal disease. J Clin Invest 126:2021-2030. https://doi.org/10.1172/JCI84419

66. Nie M, Deng Z-L, Liu J, Wang D-Z (2015) Noncoding RNAs, emerging regulators of skeletal muscle development and diseases. Biomed Res Int 2015:676575. https://doi. org/10.1155/2015/676575

67. Hagan M, Zhou M, Ashraf M, et al (2017) Long noncoding RNAs and their roles in skeletal muscle fate determination. NonCoding RNA Investig. https://doi.org/10.21037/ncri.2017.12.01

68. Cacchiarelli D, Incitti T, Martone J et al (2011) miR-31 modulates dystrophin expression: new implications for Duchenne muscular dystrophy therapy. EMBO Rep 12:136-141. https:// doi.org/10.1038/embor.2010.208

69. Hindi SM, Kumar A (2016) TRAF6 regulates satellite stem cell self-renewal and function during regenerative myogenesis. J Clin Invest 126:151-168. https://doi.org/10.1172/JCI81655

70. Ling Y-H, Sui M-H, Zheng Q et al (2018) miR-27b regulates myogenic proliferation and differentiation by targeting Pax3 in goat. Sci Rep 8:1-12. https://doi.org/10.1038/s41598-018-22262 $-4$

71. Kuang W, Tan J, Duan Y et al (2009) Cyclic stretch induced miR-146a upregulation delays C2C12 myogenic differentiation through inhibition of Numb. Biochem Biophys Res Commun 378:259-263. https://doi.org/10.1016/j.bbrc.2008.11.041

72. Khanna N, Ge Y, Chen J (2014) MicroRNA-146b promotes myogenic differentiation and modulates multiple gene targets in muscle cells. PLoS One 9:e100657. https://doi.org/10.1371/journ al.pone. 0100657

73. Kim HK, Lee YS, Sivaprasad U et al (2006) Muscle-specifi microRNA miR-206 promotes muscle differentiation. J Cell Biol 174:677-687. https://doi.org/10.1083/jcb.200603008

74. Wang XH, Hu Z, Klein JD et al (2011) Decreased miR-29 suppresses myogenesis in CKD. J Am Soc Nephrol JASN 22:20682076. https://doi.org/10.1681/ASN.2010121278

75. Naguibneva I, Ameyar-Zazoua M, Polesskaya A et al (2006) The microRNA miR-181 targets the homeobox protein HoxA11 during mammalian myoblast differentiation. Nat Cell Biol 8:278-284. https://doi.org/10.1038/ncb1373

76. Wang L, Chen X, Zheng Y et al (2012) MiR-23a inhibits myogenic diff entiation through down regulation of fast myosin heavy chain isoforms. Exp Cell Res 318:2324-2334. https://doi. org/10.1016/j.yexcr.2012.06.018

77. Antoniou A, Mastroyiannopoulos NP, Uney JB, Phylactou LA (2014) miR-186 inhibits muscle cell diff entiation through myogenin regulation. J Biol Chem 289:3923-3935. https://doi. org/10.1074/jbc.M113.507343

78. Sun Q, Zhang Y, Yang G et al (2008) Transforming growth factor- $\beta$-regulated miR-24 promotes skeletal muscle differentiation. Nucleic Acids Res 36:2690-2699. https://doi.org/10.1093/ nar/gkn032
79. Cardinali B, Castellani L, Fasanaro P et al (2009) Microrna-221 and microrna-222 modulate diff entiation and maturation of skeletal muscle cells. PLoS One 4:e7607. https://doi. org/10.1371/journal.pone.0007607

80. Eisenberg I, Eran A, Nishino I et al (2007) Distinctive patterns of microRNA expression in primary muscular disorders. Proc Natl Acad Sci 104:17016-17021. https://doi.org/10.1073/ pnas.0708115104

81. Crist CG, Montarras D, Buckingham M (2012) Muscle satellite cells are primed for myogenesis but maintain quiescence with sequestration of Myf5 mRNA targeted by microRNA-31 in mRNP granules. Cell Stem Cell 11:118-126. https://doi. org/10.1016/j.stem.2012.03.011

82. Jia L, Li Y-F, Wu G-F et al (2013) MiRNA-199a-3p regulates C2C12 myoblast diff rentiation through IGF-1/AKT/ mTOR signal pathway. Int J Mol Sci 15:296-308. https://doi. org/10.3390/ijms15010296

83. Mousavi K, Zare H, Dell'orso S et al (2013) eRNAs promote transcription by establishing chromatin accessibility at defined genomic loci. Mol Cell 51:606-617. https://doi.org/10.1016/j. molcel.2013.07.022

84. Hubé F, Velasco G, Rollin J et al (2011) Steroid receptor RNA activator protein binds to and counteracts SRA RNA-mediated activation of MyoD and muscle differentiation. Nucleic Acids Res 39:513-525. https://doi.org/10.1093/nar/gkq833

85. Borensztein M, Monnier P, Court F et al (2013) Myod and H19-Igf2 locus interactions are required for diaphragm formation in the mouse. Dev Camb Engl 140:1231-1239. https://doi. org/10.1242/dev.084665

86. Dey BK, Pfeifer K, Dutta A (2014) The H19 long noncoding RNA gives rise to microRNAs miR-675-3p and miR-675-5p to promote skeletal muscle diff entiation and regeneration. Genes Dev 28:491-501. https://doi.org/10.1101/gad.23441 9.113

87. Zhang K, Sha J, Harter ML (2010) Activation of Cdc6 by MyoD is associated with the expansion of quiescent myogenic satellite cells. J Cell Biol 188:39-48. https://doi.org/10.1083/jcb.20090 4144

88. Guo Y, Wang J, Zhu M et al (2017) Identifi of MyoDresponsive transcripts reveals a novel long non-coding RNA (lncRNA-AK143003) that negatively regulates myoblast differentiation. Sci Rep 7:2828. https://doi.org/10.1038/s41598-01703071-7

89. Wang L, Zhao Y, Bao X et al (2015) LncRNA Dum interacts with Dnmts to regulate Dppa2 expression during myogenic differentiation and muscle regeneration. Cell Res 25:335-350. https ://doi.org/10.1038/cr.2015.21

90. Lu L, Sun K, Chen X et al (2013) Genome-wide survey by ChIPseq reveals YY1 regulation of lincRNAs in skeletal myogenesis. EMBO J 32:2575-2588. https://doi.org/10.1038/emboj.2013.182

91. Chen X, He L, Zhao Y et al (2017) Malat1 regulates myogenic diff entiation and muscle regeneration through modulating MyoD transcriptional activity. Cell Discov 3:17002. https://doi. org/10.1038/celldisc.2017.2

92. Zhou L, Sun K, Zhao Y et al (2015) Linc-YY1 promotes myogenic differentiation and muscle regeneration through an interaction with the transcription factor YY1. Nat Commun 6:10026. https://doi.org/10.1038/ncomms10026

93. Yu X, Zhang Y, Li T et al (2017) Long non-coding RNA LincRAM enhances myogenic diff entiation by interacting with MyoD. Nat Commun 8:14016. https://doi.org/10.1038/ncomm s14016

94. Mueller AC, Cichewicz MA, Dey BK et al (2015) MUNC, a long noncoding RNA that facilitates the function of MyoD in skeletal myogenesis. Mol Cell Biol 35:498-513. https://doi.org/10.1128/ MCB.01079-14 
95. Wang G, Wang Y, Xiong Y et al (2016) Sirt1 AS lncRNA interacts with its mRNA to inhibit muscle formation by attenuating function of miR-34a. Sci Rep 6:21865. https://doi.org/10.1038/ srep21865

96. Zhu M, Liu J, Xiao J et al (2017) Lnc-mg is a long non-coding RNA that promotes myogenesis. Nat Commun 8:14718. https:// doi.org/10.1038/ncomms14718

97. Zhang Z, Li J, Guan D et al (2018) A newly identified lncRNA MAR1 acts as a miR-487b sponge to promote skeletal muscle differentiation and regeneration. J Cachexia Sarcopenia Muscle 9:613-626. https://doi.org/10.1002/jcsm.12281

98. Cesana M, Cacchiarelli D, Legnini I et al (2011) A long noncoding RNA controls muscle diff entiation by functioning as a competing endogenous RNA. Cell 147:358-369. https://doi. org/10.1016/j.cell.2011.09.028

99. Ballarino M, Cazzella V, D’Andrea D et al (2015) novel long noncoding RNAs (lncRNAs) in myogenesis: a miR-31 overlapping lncRNA transcript controls myoblast diff entiation. Mol Cell Biol 35:728-736. https://doi.org/10.1128/MCB.01394-14

100. Nakasa T, Ishikawa M, Shi M et al (2010) Acceleration of muscle regeneration by local injection of muscle-specific microRNAs in rat skeletal muscle injury model. J Cell Mol Med 14:2495-2505. https://doi.org/10.1111/j.1582-4934.2009.00898.x

101. Butchart LC, Terrill JR, Rossetti G et al (2018) Expression patterns of regulatory RNAs, including lncRNAs and tRNAs, during postnatal growth of normal and dystrophic (mdx) mouse muscles, and their response to taurine treatment. Int J Biochem Cell Biol 99:52-63. https://doi.org/10.1016/j.biocel.2018.03.016

102. Nghiem PP, Hoff EP, Mittal P et al (2013) Sparing of the dystrophin-deficient cranial sartorius muscle is associated with classical and novel hypertrophy pathways in GRMD dogs. Am J Pathol 183:1411-1424. https://doi.org/10.1016/j.ajpat h.2013.07.013

103. Alexander MS, Casar J, Motohashi N et al (2011) Regulation of DMD pathology by an ankyrin-encoded miRNA. Skelet Muscle 1:27. https://doi.org/10.1186/2044-5040-1-27

104. Alexander MS, Casar JC, Motohashi N et al (2014) MicroRNA486-dependent modulation of DOCK3/PTEN/AKT signaling pathways improves muscular dystrophy-associated symptoms. J Clin Invest 124:2651-2667. https://doi.org/10.1172/JCI73579

105. Alexander MS, Kawahara G, Motohashi N et al (2013) MicroRNA-199a is induced in dystrophic muscle and aff WNT signaling, cell proliferation and myogenic diff entiation. Cell Death Differ 20:1194-1208. https://doi.org/10.1038/cdd.2013.62

106. Liu J, Liang X, Zhou D et al (2016) Coupling of mitochondrial function and skeletal muscle fi type by a miR-499/Fnip1/ AMPK circuit. EMBO Mol Med 8:1212-1228. https://doi. org/10.15252/emmm.201606372

107. Dey BK, Mueller AC, Dutta A (2014) Long non-coding RNAs as emerging regulators of differentiation, development, and disease. Transcription 5:e944014. https://doi.org/10.4161/21541 272.2014.944014

108. Kyrychenko S, Kyrychenko V, Badr MA et al (2015) Pivotal role of miR-448 in the development of ROS-induced cardiomyopathy. Cardiovasc Res 108:324-334. https://doi.org/10.1093/cvr/cvv238

109. Zhou J, Gao J, Zhang X et al (2015) microRNA-340-5p functions downstream of cardiotrophin-1 to regulate cardiac eccentric hypertrophy and heart failure via target gene dystrophin. Int Heart J 56:454-458. https://doi.org/10.1536/ihj.14-386

110. Quaranta MT, Spinello I, Paolillo R et al (2016) Identifi of $\beta$-dystrobrevin as a direct target of miR-143: involvement in early stages of neural differentiation. PLoS One. https://doi. org/10.1371/journal.pone.0156325

111. Tran THT, Zhang Z, Yagi M et al (2013) Molecular characterization of an X(p21.2;q28) chromosomal inversion in a Duchenne muscular dystrophy patient with mental retardation reveals a novel long non-coding gene on Xq28. J Hum Genet 58:33-39. https://doi.org/10.1038/jhg.2012.131

112. Simionescu-Bankston A, Kumar A (2016) Noncoding RNAs in the regulation of skeletal muscle biology in health and disease. J Mol Med Berl Ger 94:853-866. https://doi.org/10.1007/s0010 9-016-1443-y

113. Cao H, Shao F, Li M et al (2019) Comprehensive identifi tion of micropeptides encoded by long noncoding RNAs in human tissues. FASEB J 33:714.1. https://doi.org/10.1096/faseb j.2019.33.1_supplement.714.1

114. Anderson DM, Anderson KM, Chang C-L et al (2015) A micropeptide encoded by a putative long noncoding RNA regulates muscle performance. Cell 160:595-606. https://doi. org/10.1016/j.cell.2015.01.009

115. Makarewich CA, Munir AZ, Schiattarella GG et al (2018) The DWORF micropeptide enhances contractility and prevents heart failure in a mouse model of dilated cardiomyopathy. eLife 7:e38319. https://doi.org/10.7554/eLife.38319

116. Lin Y-F, Xiao M-H, Chen H-X et al (2019) A novel mitochondrial micropeptide MPM enhances mitochondrial respiratory activity and promotes myogenic differentiation. Cell Death Dis. https://doi.org/10.1038/s41419-019-1767-y

117. Stein CS, Jadiya P, Zhang X et al (2018) Mitoregulin: a IncRNAencoded microprotein that supports mitochondrial supercomplexes and respiratory effi . Cell Rep 23:3710-3720.e8. https://doi.org/10.1016/j.celrep.2018.06.002

118. Matsumoto A, Clohessy JG, Pandolfi PP (2017) SPAR, a lncRNA encoded mTORC1 inhibitor. Cell Cycle 16:815-816. https://doi. org/10.1080/15384101.2017.1304735

119. Chen B, You W, Wang Y, Shan T (2019) The regulatory role of Myomaker and Myomixer-Myomerger-Minion in muscle development and regeneration. Cell Mol Life Sci. https://doi. org/10.1007/s00018-019-03341-9

120. Cai B, Li Z, Ma M et al (2017) LncRNA-Six1 encodes a micropeptide to activate Six1 in Cis and is involved in cell proliferation and muscle growth. Front Physiol. https://doi.org/10.3389/fphys .2017 .00230

121. Ma M, Cai B, Jiang L et al (2018) lncRNA-Six1 is a target of miR-1611 that functions as a ceRNA to regulate Six1 protein expression and fiber type switching in chicken myogenesis. Cells. https://doi.org/10.3390/cells7120243

122. Backes C, Meese E, Keller A (2016) Specifi miRNA disease biomarkers in blood, serum and plasma: challenges and prospects. Mol Diagn Ther 20:509-518. https://doi.org/10.1007/ s40291-016-0221-4

123. McCarthy JJ (2008) MicroRNA-206: the skeletal muscle-specific myomiR. Biochim Biophys Acta 1779:682-691. https://doi. org/10.1016/j.bbagrm.2008.03.001

124. Amirouche A, Jahnke VE, Lunde JA et al (2017) Muscle-specific microRNA-206 targets multiple components in dystrophic skeletal muscle representing beneficial adaptations. Am J Physiol-Cell Physiol 312:C209-C221. https://doi.org/10.1152/ajpcell.00185 .2016

125. Liu N, Williams AH, Maxeiner JM et al (2012) microRNA-206 promotes skeletal muscle regeneration and delays progression of Duchenne muscular dystrophy in mice. J Clin Invest 122:20542065. https://doi.org/10.1172/JCI62656

126. Ma G, Wang Y, Li Y et al (2015) MiR-206, a key modulator of skeletal muscle development and disease. Int J Biol Sci 11:345352. https://doi.org/10.7150/ijbs.10921

127. McCarthy JJ, Esser KA, Andrade FH (2007) MicroRNA-206 is overexpressed in the diaphragm but not the hindlimb muscle of mdx mouse. Am J Physiol-Cell Physiol 293:C451-C457. https ://doi.org/10.1152/ajpcell.00077.2007

128. Yuasa K, Hagiwara Y, Ando M et al (2008) MicroRNA-206 is highly expressed in newly formed muscle fi implications 
regarding potential for muscle regeneration and maturation in muscular dystrophy. Cell Struct Funct 33:163-169. https://doi. org/10.1247/csf.08022

129. Coenen-Stass AML, Wood MJA, Roberts TC (2017) Biomarker potential of extracellular miRNAs in duchenne muscular dystrophy. Trends Mol Med 23:989-1001. https://doi.org/10.1016/j. molmed.2017.09.002

130. Coenen-Stass AML, Betts CA, Lee YF et al (2016) Selective release of muscle-specific, extracellular microRNAs during myogenic differentiation. Hum Mol Genet 25:3960-3974. https://doi. org/10.1093/hmg/ddw237

131. Vignier N, Amor F, Fogel P et al (2013) Distinctive serum miRNA profi in mouse models of striated muscular pathologies. PLoS One 8:e55281. https://doi.org/10.1371/journ al.pone.0055281

132. Hu J, Kong M, Ye Y et al (2014) Serum miR-206 and other muscle-specifi microRNAs as non-invasive biomarkers for Duchenne muscular dystrophy. J Neurochem 129:877-883. https ://doi.org/10.1111/jnc.12662

133. Cacchiarelli D, Legnini I, Martone J et al (2011) miRNAs as serum biomarkers for Duchenne muscular dystrophy: miRNAs as serum biomarkers for DMD. EMBO Mol Med 3:258-265. https ://doi.org/10.1002/emmm.201100133

134. Li X, Li Y, Zhao L et al (2014) Circulating muscle-specific miRNAs in Duchenne muscular dystrophy patients. Mol Ther Nucleic Acids 3:e177. https://doi.org/10.1038/mtna.2014.29

135. Matsuzaka Y, Kishi S, Aoki Y et al (2014) Three novel serum biomarkers, miR-1, miR-133a, and miR-206 for Limb-girdle muscular dystrophy, Facioscapulohumeral muscular dystrophy, and Becker muscular dystrophy. Environ Health Prev Med 19:452-458. https://doi.org/10.1007/s12199-014-0405-7

136. Anaya-Segura M, Rangel-Villalobos H, Martínez-Cortés G et al (2016) Serum levels of MicroRNA-206 and novel mini-STR assays for carrier detection in duchenne muscular dystrophy. Int J Mol Sci 17:1334. https://doi.org/10.3390/ijms17081334

137. Roberts TC, Blomberg KEM, McClorey G et al (2012) Expression analysis in multiple muscle groups and serum reveals complexity in the MicroRNA transcriptome of the mdx mouse with implications for therapy. Mol Ther Nucleic Acids 1:e39. https:// doi.org/10.1038/mtna.2012.26

138. Mizuno H, Nakamura A, Aoki Y et al (2011) Identifi of muscle-specific MicroRNAs in serum of muscular dystrophy animal models: promising novel blood-based markers for muscular dystrophy. PLoS One 6:e18388. https://doi.org/10.1371/journ al.pone.0018388

139. Deng Z, Chen J-F, Wang D-Z (2011) Transgenic overexpression of miR-133a in skeletal muscle. BMC Musculoskelet Disord. https://doi.org/10.1186/1471-2474-12-115

140. Zacharewicz E, Lamon S, Russell A (2013) MicroRNAs in skeletal muscle and their regulation with exercise, ageing, and disease. Front Physiol 4:266. https://doi.org/10.3389/fphys.2013.00266

141. Gomes CPC, Oliveira GP, Madrid B et al (2014) Circulating miR-1, miR-133a, and miR-206 levels are increased after a half-marathon run. Biomark Biochem Indic Expo Response Susceptibil Chem 19:585-589. https://doi.org/10.3109/13547 50X.2014.952663

142. Llano-Diez M, Ortez CI, Gay JA et al (2017) Digital PCR quantifi of miR-30c and miR-181a as serum biomarkers for Duchenne muscular dystrophy. Neuromuscul Disord 27:15-23. https://doi.org/10.1016/j.nmd.2016.11.003

143. Jeanson-Leh L, Lameth J, Krimi S et al (2014) Serum profi ing identifies novel muscle miRNA and cardiomyopathy-related miRNA biomarkers in golden retriever muscular dystrophy dogs and duchenne muscular dystrophy patients. Am J Pathol 184:2885-2898. https://doi.org/10.1016/j.ajpath.2014.07.021
144. Roberts TC, Godfrey C, McClorey G et al (2013) Extracellular microRNAs are dynamic non-vesicular biomarkers of muscle turnover. Nucleic Acids Res 41:9500-9513. https://doi. org/10.1093/nar/gkt724

145. Catapano F, Domingos J, Perry M et al (2018) Downregulation of miRNA-29, -23 and -21 in urine of Duchenne muscular dystrophy patients. Epigenomics. https://doi.org/10.2217/ epi-2018-0022

146. Becker S, Florian A, Patrascu A et al (2016) Identifi of cardiomyopathy associated circulating miRNA biomarkers in patients with muscular dystrophy using a complementary cardiovascular magnetic resonance and plasma profiling approach. J Cardiovasc Magn Reson. https://doi.org/10.1186/s1296 8-016-0244-3

147. Grounds MD, Terrill JR, Al-Mshhdani BA et al (2020) Biomarkers for Duchenne muscular dystrophy: myonecrosis, inflammation and oxidative stress. Dis Model Mech. https://doi. org/10.1242/dmm.043638

148. Cazzella V, Martone J, Pinnarò C et al (2012) Exon 45 skipping through U1-snRNA antisense molecules recovers the Dys-nNOS pathway and muscle differentiation in human DMD myoblasts. Mol Ther 20:2134-2142. https://doi.org/10.1038/mt.2012.178

149. Roberts TC, Johansson HJ, McClorey G et al (2015) Multi-level omics analysis in a murine model of dystrophin loss and therapeutic restoration. Hum Mol Genet 24:6756-6768. https://doi. org/10.1093/hmg/ddv381

150. Young CS, Hicks MR, Ermolova NV et al (2016) A single CRISPR-Cas9 deletion strategy that targets the majority of DMD patients restores dystrophin function in hiPSC-derived muscle cells. Cell Stem Cell 18:533-540. https://doi.org/10.1016/j. stem.2016.01.021

151. Hildyard JC, Wells DJ (2016) Investigating synthetic oligonucleotide targeting of Mir31 in Duchenne muscular dystrophy. PLoS Curr. https://doi.org/10.1371/currents.md.99d88e7263 4387639707601b237467d7

152. Heller KN, Mendell JT, Mendell JR, Rodino-Klapac LR (2017) MicroRNA-29 overexpression by adeno-associated virus suppresses fibrosis and restores muscle function in combination with microdystrophin. JCI Insight. https://doi.org/10.1172/jci.insight.93309

153. Bulaklak K, Xiao B, Qiao C et al (2018) MicroRNA-206 downregulation improves therapeutic gene expression and motor function in mdx mice. Mol Ther Nucleic Acids 12:283-293. https:// doi.org/10.1016/j.omtn.2018.05.011

154. Perkins KJ, Davies KE (2018) Alternative utrophin mRNAs contribute to phenotypic diff ences between dystrophin-defi mice and Duchenne muscular dystrophy. FEBS Lett 592:18561869. https://doi.org/10.1002/1873-3468.13099

155. Basu U, Lozynska O, Moorwood C et al (2011) Translational regulation of utrophin by miRNAs. PLoS One 6:e29376. https:// doi.org/10.1371/journal.pone.0029376

156. Mishra MK, Loro E, Sengupta K et al (2017) Functional improvement of dystrophic muscle by repression of utrophin: let7c interaction. PLoS One 12:e0182676. https://doi.org/10.1371/ journal.pone. 0182676

157. Aminzadeh MA, Rogers RG, Fournier M et al (2018) Exosomemediated benefits of cell therapy in mouse and human models of duchenne muscular dystrophy. Stem Cell Rep 10:942-955. https ://doi.org/10.1016/j.stemcr.2018.01.023

158. Roberts TC, Coenen-Stass AML, Wood MJA (2014) Assessment of RT-qPCR normalization strategies for accurate quantifi tion of extracellular microRNAs in murine serum. PLoS One 9:e89237. https://doi.org/10.1371/journal.pone.0089237 